\title{
DNA diversity in Hawaiian endemic plant Schiedea globosa
}

\author{
DA Filatov and S Burke \\ School of Biosciences, University of Birmingham, Edgbaston, Birmingham B15 2TT, UK
}

This is the first report of a study devoted to the population genetics of speciation in the endemic Hawaiian plant genus Schiedea (Caryophyllaceae). Here, we report the estimates of DNA sequence diversity and divergence in a newly isolated nuclear gene from Maui and Oahu Schiedea globosa populations. Overall, the species-wide average heterozygosity per silent site is $\pi=0.3 \%$. The silent DNA diversity on the older island of Oahu $(\pi=0.24 \%)$ is almost twice as high as on the younger Maui $(\pi=0.14 \%)$. Consistent with this, the haplotype phylogeny suggests a more recent origin of the Maui populations. There is no significant isolation between the two Maui populations $\left(F_{\mathrm{st}}=0.027\right)$, while isolation between the two islands is high $\left(F_{\mathrm{st}}=0.57, P<0.0001\right)$.
Pairwise mismatch distributions suggest population growth approximately 660 and 310 thousand generations ago for the Oahu and the Maui populations, respectively, which may be the minimal age for these populations. This is consistent with a fairly neutral frequency spectrum (Tajima's $D$ is 0.34 and -0.94 for the Oahu and the Maui populations, respectively), suggesting that both populations are sufficiently old to have recovered from any initial founder effects. Relatively high nuclear DNA diversity in the $S$. globosa populations illustrates the usefulness of a DNA sequence-based approach to the population genetics of island plant populations.

Heredity (2004) 92, 452-458, advance online publication, 10 March 2004; doi:10.1038/sj.hdy.6800440

Keywords: population genetics; speciation; Hawaii; DNA diversity; Schiedea

\section{Introduction}

Hawaiian flora and fauna are unique in the number of species that are endemic to the archipelago. Many groups of animals and plants have undergone speciation bursts, providing model systems for evolutionary biologists to study the speciation processes. Studies of Hawaiian biogeography (see, for a review, Funk and Wagner, 1995) suggest that the geological history of the archipelago is one of the main causes of frequent speciation events.

Tectonic plate movement over the volcanic hotspot underlying the Hawaiian archipelago results in a continuous generation of new islands at the south east end of the archipelago. The islands erode and subside with time, forming a giant 'habitat conveyor belt', with older eroded low islands on the north west, and young active volcanoes to the south east (Carson and Clague, 1995). Continuous changing of the environment on the islands coupled with colonization of the new islands and fragmented geographic range are, probably, conditions that force organisms to change quickly, yielding new species (Hollocher, 1996).

The speciation process for Hawaiian plants is poorly understood. It is not clear whether the speciation occurs due to adaptation to the continuously changing environment (adaptation model of speciation), due to a founder effect during colonization of the new islands (founder effect model of speciation) as suggested by Carson (1968) and Templeton (1980), or whether Hawaiian speciation

Correspondence: DA Filatov, School of Biosciences, University of Birmingham, Edgbaston, Birmingham B15 2TT, UK.

E-mail:d.filatov@bham.ac.uk

Received 11 September 2002; accepted 27 January 2004; published online 10 March 2004 follows the classical allopatric model of speciation (Mayr, 1963) with geographic barriers to gene flow between populations and slow divergence being the main causes of speciation. Indeed, colonization of a new island may result simultaneously in a drastic change in environmental conditions, in a founder effect and in the creation of geographic barriers to gene flow between new and old populations.

The speciation process has been studied in different groups of organisms endemic to the Hawaiian archipelago with most efforts being focused on Hawaiian Drosophila, which include several hundred species. In many cases, speciation has been found to be due to 'island hopping'; speciation with new species formed after colonization events (Hollocher, 1996), in which sexual selection played an important role (Carson, 1997). Other groups of organisms have been studied in much less detail, and work has been mostly devoted to the phylogenetic relationships and the biogeography of certain groups of species (Wagner and Funk, 1995). The few available results provide support for the 'island hopping' model for most of the studied organisms (Funk and Wagner, 1995).

The genus Schiedea (Caryophyllaceae) includes over 30 species endemic to Hawaii, and represents striking diversity in morphology, breeding system and habitat (Wagner et al, 1995). This genus is a convenient model to study the speciation process, since it represents one of the largest recent adaptive plant radiations on Hawaii and substantial work has been devoted to characterize its phylogenetics and biogeography (Wagner et al, 1995; Weller et al, 1995, 1996; Soltis et al, 1996; Sakai et al, 1997). Here, we report the level and the patterns of nuclear DNA diversity and divergence in the populations of 
S. globosa from Oahu and Maui islands. S. globosa is subdioecious with separate males and females and rare occurrences of hermaphroditic individuals (Weller et al, 1995). Hence a reduction in genetic diversity due to selfing (eg Liu et al, 1999) is limited in this species, simplifying the analysis and the interpretation of the results. Unlike most other Schiedea species, S. globosa inhabits several islands in the Hawaiian archipelago; besides Maui and Oahu it has been found on Molocai and on the Big Island of Hawaii (Steve Weller, personal communication). S. globosa populations from different islands were suggested to be separate species (Soltis et al, 1996), but are currently being treated as populations of the same species because they cannot be reliably distinguished (Steve Weller, personal communication). The data presented here suggest that Oahu and Maui populations of $S$. globosa are fairly isolated from each other, and are probably diverging into separate species. We also present the nuclear DNA diversity-based inferences of age and population dynamics for these populations.

\section{Methods}

Schiedea globosa plants from two Maui populations and one Oahu population, as well as a frozen leaf sample of one $S$. adamantis plant were kindly provided by Drs S Weller and A Sakai, University of California Irvine, California, USA. The S. globosa samples from Molocai and the Big Island of Hawaii are currently not available (Steve Weller, personal communication). Total genomic DNA was extracted from leaf material according to the CTAB plant miniprep method as described before (Filatov and Charlesworth, 1999).

No gene sequences had been available from the Schiedea genus. In order to isolate new genes from Schiedea, we used Silene latifolia primers XY1 +3 and XY1-10 (Filatov et al, 2001), which amplified a region of $3.5 \mathrm{~kb}$ from S. globosa. The PCR product was cloned using TA-cloning kit (Invitrogen) and sequenced by a 'sequence walk', starting from both ends with the XY1 3 and XY1-10 primers and ordering new internal sequencing primers using the sequence information from the previous sequence reads. As the original Silene PCR primers, XY1 +3 and XY1-10 worked only for some individuals, for the population diversity study, we used a different forward primer, SgXY1 + 31 (GCAACACATACTGACAGTCC) together with the original $X Y 1-10$ reverse primer
(TCCAGCAGAGCTTGAACAGTCT), which amplified a region of about $3 \mathrm{~kb}$ consistently from all the $S$. globosa individuals. For the PCR amplification, we used High Fidelity kit (Roche) with the following PCR conditions: one cycle of $95^{\circ} \mathrm{C}, 30 \mathrm{~s}, 58^{\circ} \mathrm{C}, 30 \mathrm{~s}, 68^{\circ} \mathrm{C}, 4 \mathrm{~min}$ followed by 35 cycles of $95^{\circ} \mathrm{C}, 30 \mathrm{~s}, 56^{\circ} \mathrm{C}, 30 \mathrm{~s}, 68^{\circ} \mathrm{C}, 3.5 \mathrm{~min}$. The PCR products were extracted from the agarose gels using the Qiagen gel extraction kit and cloned using TA-cloning kit (Invitrogen). Sequencing was performed using ABI BigDye v2 system on the ABI3700 automated sequencing machine with the following primers: SgXY1+31 (see above), SgXY1 + 33 (CTATGTGCTCTTCTGAACCGC), SgXY1 + 29 (TTGGACCTCGTGGCATCTAT), SgXY1-30 (CAATTTCAACTTCCTTGGATGTA), SgXY1 + 34 (GAT GCAAGAGTTGGATTGGCAC), SgXY1-27 (AAGCGAG GCAAACCCAAATG), SgXY1 + 35 (GTCATGATGCTC CTGTCCTTTG), XY1-10 (see above). In all the primers ' + ' indicates forward and ' - ' indicates reverse orientation. ABI sequence chromatograms were checked and corrected, and the contigs were assembled using ProSeq v3 software (Filatov, 2002). PCR amplification is not $100 \%$ error free, and sequencing of the cloned PCR products may result in a bias due to PCR errors. Therefore, every polymorphic site in the data set was double checked by additional amplification and sequencing. The same primers were used to isolate and sequence the homologous gene from $S$. adamantis.

Sequences were aligned using ClustalX v1.64 (Thomson et al, 1997) followed by manual adjustment using ProSeq v3 (Filatov, 2002). Estimates of nucleotide diversity, Tajima's $D$ neutrality test (Tajima, 1989), population subdivision and gene flow statistics, and permutation-based tests of significance (Hudson et al, 1992) were performed using ProSeq v3. Both nucleotide substitutions and insertion/deletion (indels) sites were taken into account in these analyses. The significance of the Tajima's neutrality test was assessed by coalescent simulations without recombination using ProSeq v3. The neighbor-joining tree was created using MEGA (Kumar et al, 1993). To conduct the $F_{\mathrm{s}}$ neutrality test $(\mathrm{Fu}, 1997)$ and to estimate the time since the population expansion from the pairwise mismatch distribution, we used Arlequin software (Excoffier, 2000). The Fay and Wu's (2000) neutrality test was conducted by a Cprogram kindly provided by J Fay. The distributions of Tajima's $D$ for different times since population growth were generated using the coalescent simulations tool in ProSeq v3 (Filatov, 2002).

Table 1 DNA diversity in Maui and Oahu populations of S. globosa

\begin{tabular}{|c|c|c|c|c|c|c|c|c|}
\hline & \multirow[b]{2}{*}{$\mathrm{N}^{\mathrm{b}}$} & \multicolumn{2}{|c|}{ Silent $(\mathrm{L}=2318.02)^{\mathrm{a}}$} & \multicolumn{2}{|c|}{ Nonsilent $(\mathrm{L}=629.98)^{\mathrm{a}}$} & \multicolumn{3}{|c|}{ Total $(\mathrm{L}=2948)^{\mathrm{a}}$} \\
\hline & & $\mathrm{S}^{c}$ & $\pi^{\mathrm{d}}$ & $\mathrm{S}^{\mathrm{c}}$ & $\pi^{\mathrm{d}}$ & $\mathrm{S}^{\mathrm{c}}$ & $\pi^{\mathrm{d}}$ & Tajima's D \\
\hline Oahu & 12 & 15 & $2.4 \pm 1.11$ & 2 & $0.9 \pm 0.54$ & 17 & $2.1 \pm 0.99$ & 0.33 \\
\hline Maui pooled & 23 & 15 & $1.4 \pm 0.87$ & 2 & $0.3 \pm 0.43$ & 17 & $1.2 \pm 0.77$ & -0.94 \\
\hline Maui-1 & 18 & 13 & $1.5 \pm 0.82$ & 1 & $0.2 \pm 0.23$ & 14 & $1.2 \pm 0.69$ & -0.54 \\
\hline Maui-2 & 5 & 6 & $1.1 \pm 0.75$ & 1 & $0.6 \pm 0.46$ & 7 & $1.0 \pm 0.69$ & -0.75 \\
\hline Total & 35 & 33 & $3 \pm 1.68$ & 4 & $0.5 \pm 0.75$ & 37 & $2.5 \pm 1.48$ & -0.68 \\
\hline
\end{tabular}

aNumber of positions analyzed.

${ }^{b}$ Number of individuals sampled.

'Number of segregating sites observed.

dAverage heterozygosity per 1000 sites. $\pi$ is an estimator of $\theta=4 N u$, scaled mutation rate. 


\section{Results}

Isolation of the S. globosa gene

As no Schiedea sequences were available, we isolated a new region of about $3 \mathrm{~kb}$ long from $S$. globosa as described in the Methods section. The newly isolated genomic region was homologous to the Silene latifolia SlX1 and SlY1 genes (Delichère et al, 1999; Filatov et al, 2000), thus the new S. globosa homolog was named SgXY1. The regions corresponding to the exons in Silene genes were conserved in the $S$. globosa homolog, while the introns between Schiedea and Silene genes were almost unalignable. As the open-reading frame in the $S g X Y 1$ was preserved, we concluded that this gene might be functional in $S$. globosa, or have been functional very recently. According to our Southern blot analysis, $S g X Y 1$ is a single-copy gene in S. globosa.

The divergence between Silene and Schiedea homologous sequences was estimated to be $45.7 \%$ at synonymous sites and $4.54 \%$ at nonsynonymous sites. This divergence is consistent with the view that Schiedea is fairly divergent from the other Caryophyllaceae genera (Soltis et al, 1996). The low ratio of replacement over silent divergence $\left(K_{\mathrm{a}} / K_{\mathrm{s}}=0.099\right)$ suggests that $S g X Y 1$ is not a pseudogene in Schiedea. We also sequenced the same $3 \mathrm{~kb}$ long region of the $S g X Y 1$ gene from another Schiedea species, S. adamantis. The intron divergence between this species and S. globosa was $1.1 \pm 0.2 \%$. No amino-acid substitutions were observed, also suggesting that the Schiedea $S g X Y 1$ gene is under purifying selection.

\section{Sequence diversity in $S$. globosa}

The new gene isolated from S. globosa was used to study the DNA diversity in three $S$. globosa populations, one from Oahu and two from Maui islands. In total, we analyzed sequences of approximately $3 \mathrm{~kb}$ long for 35 alleles isolated from 12 plants from Oahu and 23 plants from the two Maui populations (Table 1). Overall, the DNA diversity in S. globosa $\left(\pi_{\mathrm{s}}=0.3 \%\right)$ was lower than in Drosophila (Moriyama and Powell, 1995) and comparable to that in humans (Aquadro et al, 2001). The two Maui populations demonstrated no significant isolation $\left(F_{\mathrm{st}}=0.027, \mathrm{NS}\right)$, thus in all the further analyses all the Maui sequences will be pooled together. The isolation between the Maui and the Oahu populations is quite high, $F_{\mathrm{st}}=0.57, P<0.0001$, suggesting that the gene flow between the islands is very low. The diversity on Maui $\left(\pi_{\mathrm{s}}=0.14 \%\right)$ is substantially lower than in the Oahu population $\left(\pi_{\mathrm{s}}=0.24 \%\right.$, Table 1$)$.

All the Maui haplotypes cluster together and form a clade within the more diverse Oahu clade (Figure 1), suggesting that the Oahu population is older and, perhaps, Maui was colonized from Oahu. Consistent with this, the diversity in the Oahu population is significantly higher than in either of the two Maui populations, and in both Maui populations pooled (Table 1). The higher diversity in the Oahu population is mainly due to clustering of the sequences into two clades differing by 12 nucleotide substitutions (Figure 1). Although the smaller Oahu clade (including Sg1, Sg6 and Sg12) clusters with Maui haplotypes, this clade is more diverged from the sequences from the Maui population, compared to the larger Oahu clade (average pairwise

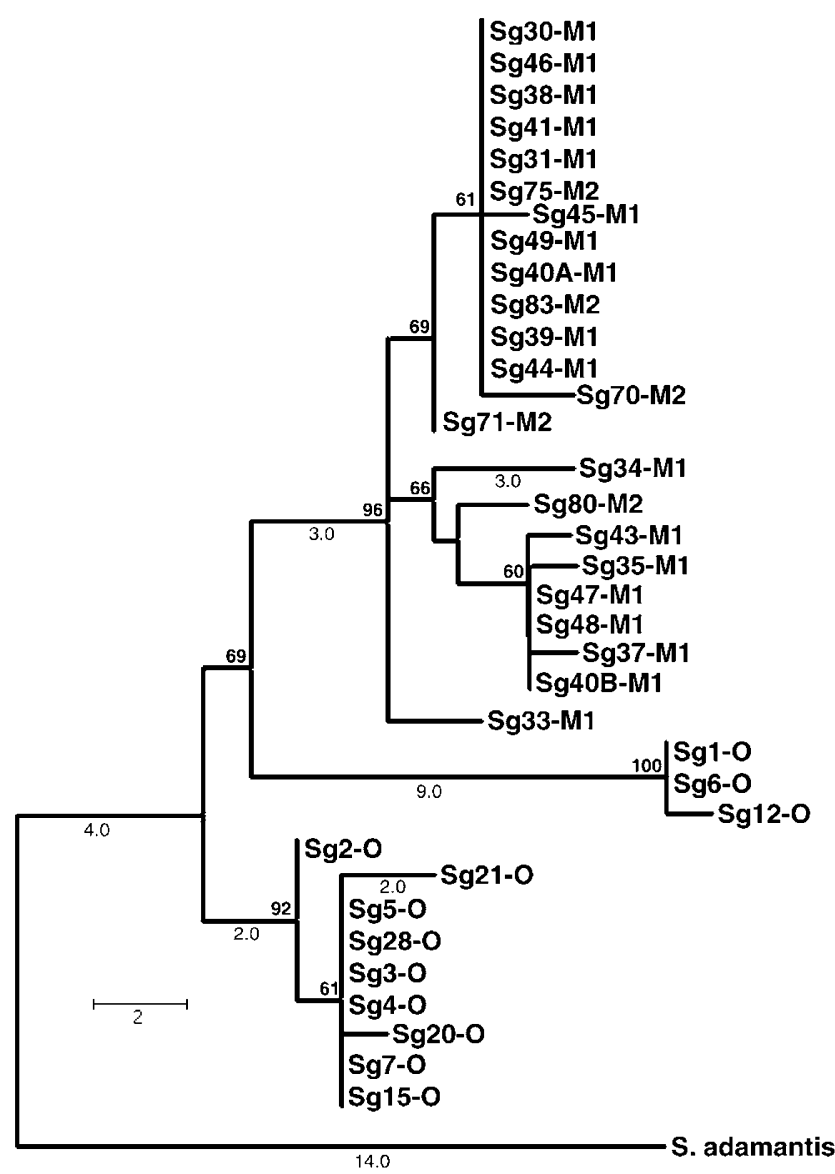

Figure 1 Neighbor-joining tree for the S. globosa nuclear gene $S g X Y 1$ from Maui (nodes marked with 'M1' or 'M2') and Oahu (nodes marked with ' $\mathrm{O}$ ') populations, rooted by a single sequence from $S$. adamantis. The genetic distance (the number of nucleotide substitutions) is shown below the branches. Bootstrap support (\%) is shown above the branches.

divergence per nucleotide, $D_{x y}=0.0051$ and 0.0033 , respectively).

If the island populations are formed by colonization, we would expect population growth to follow the colonization of a new island. Population growth results in star-like phylogenies with the biased frequency spectrum of polymorphisms (Hudson, 1990; Braverman et al, 1995), which can be detected by negative values of the Tajima's $D$ statistic (Tajima, 1989). Tajima's $D$ is not significantly negative for the Oahu $(D=0.34)$ or for the Maui $(D=-0.94)$ populations. Another statistic, Fu's $F_{\mathrm{s}}$ was shown to be particularly sensitive for the recent population expansions ( $\mathrm{Fu}, 1997)$. This statistic is based on the number of haplotypes observed in the sample, which is expected to be inflated by a recent population growth. Fu's $F_{\mathrm{s}}$ is not significant for the Oahu population $\left(F_{\mathrm{s}}=4.17\right)$. For the Maui population, however, $F_{\mathrm{s}}$ does detect a significant excess of the number of haplotypes $\left(F_{\mathrm{s}}=-3.72, P=0.03\right)$, suggesting a recent population growth, or a selective sweep in or near the $S g X Y 1$ gene. Fay and Wu's (2000) $H$ statistic was demonstrated to be sensitive to the footprints of a recent selective

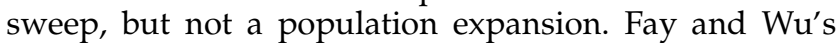
$H$ statistic was not significant in the Maui or in the Oahu populations. 
Age of the populations

As these were not significantly negative values of Tajima's $D$ for either Maui or Oahu populations, the results suggest that these populations are sufficiently old for the frequency spectrum to have recovered after the founder effect and the population growth. Assuming a model of an exponential population growth after a founder effect, we can estimate the minimal age of the population as the minimal time since the population growth, which is compatible with the observed values of the Tajima's $D$ statistic. We ran coalescent simulations with exponential population growth between 0.1 and $4 N_{\mathrm{e}}$ generations ago (Figure 2). The observed values of Tajima's $D$ were incompatible with a population growth less than 0.9 and $0.6 N_{\mathrm{e}}$ generations ago for the Oahu and the Maui populations, respectively.

Rogers and Harpending (1992) demonstrated that the shape of the distribution of the number of observed differences between the pairs of the nonrecombining DNA sequences (mismatch distribution) reflects the past population dynamics, in particular, population expansion generates a wave in the mismatch distribution. This wave travels to the right with time since the population expansion and the position of the wave allows the timing of the population expansion to be estimated (Rogers and Harpending, 1992). The pairwise mismatch distribution for the Maui and the Oahu S. globosa populations is shown in Figure 3. Both populations show a peak of mismatch distributions around 6 and 11 mismatches
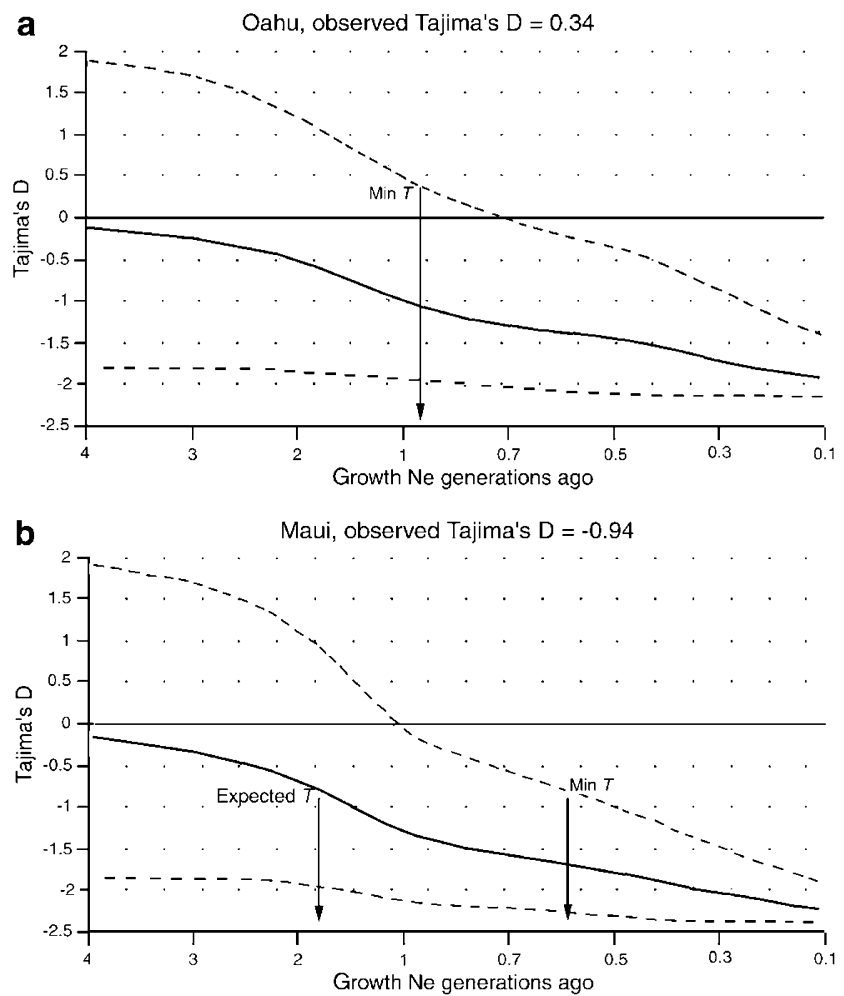

Figure 2 Simulated distributions of Tajima's $D$ statistic (Tajima, 1989) for different times since the population expansion. The solid and the dotted lines are the mean and the 2.5 and $97.5 \%$ percentiles of the distribution of Tajima's D. The vertical arrows show the minimal and the expected time since the population expansion. Only minimal time since the population expansion is shown for the Oahu population (plot A), as the growth in that population is apparently too old to be detected by the Tajima's $D$ statistic.

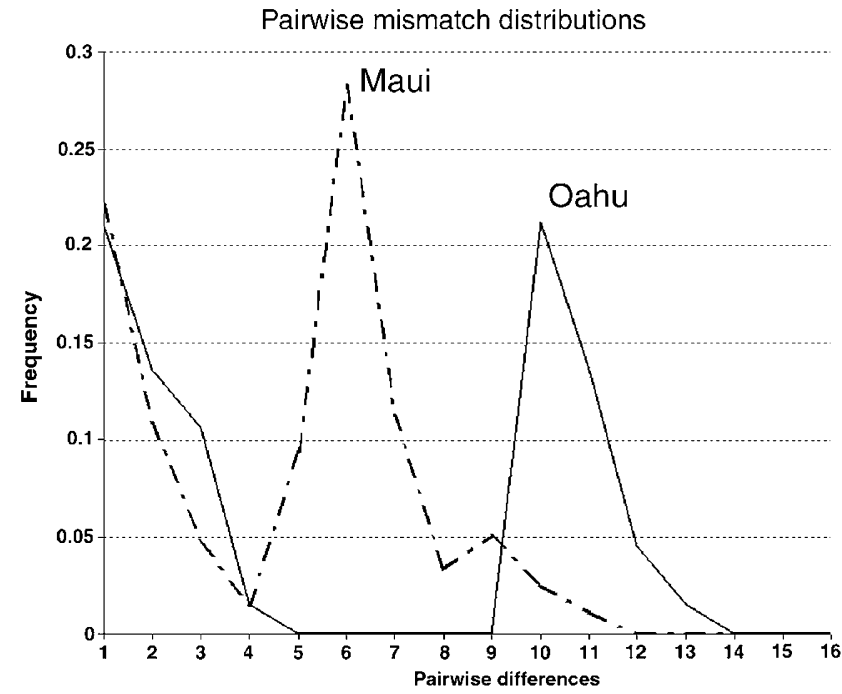

Figure 3 Pairwise mismatch distributions (Rogers and Harpending, 1992) for the Oahu and the Maui populations.

for the Maui and the Oahu populations, respectively. To estimate the time and the scale of the population expansion in these populations, we fitted the stepwise demographic expansion model to the data as described by Schneider and Excoffier (1999). The time of the expansion, measured in mutational units, $\tau=2 u t(99 \%$ conf. interval), is $\tau=6.26(1.32-19.13)$ for the Maui, and $\tau=11.18(6.42-21.16)$ for the Oahu populations, respectively.

\section{Discussion}

Despite the abundance of molecular phylogenetic data for many Hawaiian plants (Pax et al, 1997; Baldwin and Sanderson, 1998; Cross and Motley, 2000; Lindqvist and Albert, 2002), there is surprisingly little information on the intraspecific DNA diversity in Hawaiian, and more generally, island plant populations. This is probably because it is generally assumed that intraspecific diversity in the populations of island endemic plants is very low (Barrett and Husband, 1990), which seems quite logical, given that the lack of resolution in DNA-based phylogenies is a common problem in phylogenetic studies of island plant radiations. Hence, the intraspecific genetic diversity data are mostly based on allozyme diversity (Helenurm and Ganders, 1985; Weller et al, 1996; Marr and Bohm, 1999), which may be quite misleading due to possible non-neutrality of charge changing amino-acid replacements creating allozyme diversity (Hudson et al, 1994; Veuille and King, 1995; Eanes et al, 1996; Filatov and Charlesworth, 1999). Here, we reported one of the first DNA sequence-based estimates of genetic diversity in Hawaiian plants. The only other estimate of Hawaiian plant DNA diversity was recently published for silverswords Argyroxiphium sandwicense and Dubautia ciliolata (Lawton-Rauh et al, 2003). The DNA diversity in the $S$. globosa and silverswords populations appears to be quite similar, $\pi \sim 0.03 \%$. This value is also comparable to the DNA diversity observed in selfing Arabidopsis thaliana (Kuittinen and Aguade, 2000; Aguade, 2001), Hordeum vulgare (Cummings and Clegg, 1998) and Pennisetum glaucum 
(Gaut and Clegg, 1993), outcrossing A. lyrata (Savolainen et al, 2000) and dioecious Dioscorea tokoro (Terauchi et al, 1997), but lower than in outcrossing Leavenworthia stylosa (Filatov and Charlesworth, 1999) and in dioecious Silene latifolia (Filatov et al, 2000, 2001).

Although we only studied the diversity at a single locus, our estimate could reflect the average DNA diversity across the genome because the DNA diversity in the $S$. globosa $S g X Y 1$ gene is in close agreement with previous estimates of allozyme diversity in this species (Weller et al, 1996). Indeed, in the Oahu population nonsilent DNA diversity is $\pi=0.9$ per 1000 nucleotides (Table 1), or approximately one replacement in 300 amino acids. Assuming the average protein size of 500 1000 amino acids and taking into account that only a fraction of amino-acid replacements is detectable by electrophoresis, we get a similar diversity figure for the allozyme heterozygosity as reported by Weller et al (1996). As the allozyme diversity in S. globosa was demonstrated to be fairly similar to the other species in the genus (Weller et al, 1996), the level of DNA diversity seen in the $S$. globosa $S g X Y 1$ gene is probably typical for many other Schiedea species.

Consistent with the allozyme data (Weller et al, 1996), the diversity in the Maui population appeared to be about two-fold lower than in the Oahu population (Table 1). The Maui populations are not smaller than the population on Oahu (S Weller, persoanl communication), so the lower genetic diversity on Maui may reflect a more recent origin of the Maui populations. The haplotype phylogeny is consistent with this, as the sequences from the Maui populations cluster together within the larger Oahu cluster (Figure 1). If the diversity in the Maui population is reduced due to a recent population bottleneck, this should result in the excess of rare polymorphic sites, which could be detected by the negative values of Tajima's $D$ (Tajima, 1989) or Fu's $F_{\mathrm{s}}(\mathrm{Fu}, 1997)$ statistics. Although Tajima's $D$ is not significantly negative, the more sensitive $F_{\mathrm{s}}$ statistic does show a significantly negative value for the Maui population. This could be due to a recent population growth after a bottleneck, or due to a selective sweep in the Maui population. We cannot detect any signature of a selective sweep by the Fay and Wu's (2000) H statistic, which is known to be very sensitive to the selective sweeps; thus, the recent population growth seems a more probable explanation for the negative $F_{\mathrm{s}}$ value in the Maui population.

The age of the populations was estimated using two methods: (i) coalescent simulations with exponential growth (Hudson, 1990) and (ii) the pairwise mismatch distribution (Rogers and Harpending, 1992). Both methods consistently suggest a younger age for the Maui population. The age estimates, however, are in terms of the number of effective population sizes for the first method and in mutational units for the second one. To translate these estimates into the number of generations, we assume per locus per generation mutation rate to be of the order of $10^{-5}$. The effective population sizes can be estimated from $E\left(N_{\mathrm{e}}\right)=E(\theta) / 4 u$, and are equal to $0.6 \times 10^{5}$ and $1.4 \times 10^{5}$ individuals for the Maui and the Oahu populations, respectively. For the Oahu population, the expected time since growth exceeds $4 N_{\mathrm{e}}$ generations, allowing only the minimal time since the expansion in the Oahu population to be estimated $\left(T_{\min }=126000\right.$ generations). For the Maui population, the growth is apparently more recent, allowing the expected and the minimal times since the population expansion to be estimated $\left(T_{\exp }=120000, T_{\min }=36000\right.$ generations). Assuming the same mutation rate, the pairwise mismatch distribution suggests that the population growth on Maui occurred 310 (70-960) thousand generations ago (KGA), while in the Oahu population it happened around 560 (320-1060) KGA. The estimates of the time since the population expansions obtained by the two methods are not wildly different from each other, and agree with the lower DNA diversity in the Maui population.

We detected a highly significant isolation between the Maui and the Oahu populations $\left(F_{\mathrm{st}}=0.57, P<0.0001\right)$, suggesting that the populations on different islands are completely isolated geographically. It seems unlikely that this isolation is due to genetic or ecotypic incompatibilities of the two populations, which are crossfertile (Weller et al, 2001).

No polymorphic sites were shared and only three sites were fixed between the Maui and Oahu populations, with most polymorphisms occurring exclusively either on Maui or on Oahu (17 and 17 sites, respectively). This suggests that the populations have gone through a bottleneck, causing the loss of ancestral polymorphism (hence no shared polymorphisms), and the independent accumulation of mutations in the two populations. On the other hand, the two populations might have diverged fairly recently, so there was not enough time for the populations to accumulate many fixed differences. This is consistent with the scenario of a formation of the Maui population due to a colonization event, which resulted in a substantial loss of ancestral genetic diversity and the subsequent accumulation of differences in isolation. This might be a typical pattern for the entire genus, because most Schiedea species were probably formed after colonization of the new islands (Wagner et al, 1995).

The colonization and bottleneck events may result in a substantial reduction of genetic diversity. On the other hand, in some cases bottlenecks can increase additive genetic variance and hence the capacity of populations to adapt to new environments (eg Fernandez et al, 1995; Meffert, 2000). It remains to be demonstrated whether this is the factor that promotes speciation on islands, as suggested by Templeton (1980), or the new species are formed due to geographic isolation between the islands according to Mayr's (1963) classic model of allopatric speciation. The demonstration of almost complete geographical isolaton of the two island S. globosa populations and the lack of any evidence of adaptation to different environments makes Mayr's (1963) model of allopatric divergence a more plausible scenario for this species.

\section{Acknowledgements}

We thank Steve Weller and Ann Sakai for providing the plant material and Joe Ironside and Steve Weller for critical reading of the paper. This work was supported by a grant to DAF from the Leverhulme Trust.

\section{References}

Aguade M (2001). Nucleotide sequence variation at two genes of the phenylpropanoid pathway, the $F A H 1$ and $F 3 H$ genes, in Arabidopsis thaliana. Mol Biol Evol 18: 1-9. 
Aquadro CF, DuMont VB, Reed FA (2001). Genome-wide variation in the human and fruitfly: a comparison. Curr Opin Genet Dev 11: 627-634.

Baldwin BG, Sanderson MJ (1998). Age and rate of diversification of the Hawaiian silversword alliance. Proc Natl Acad Sci USA 95: 9402-9406.

Barrett SCH, Husband BC (1990). The genetics of plant migration and colonisation. In: Brown AHD, Clegg MT, Kahler AL, Weir BS (eds) Plant: Population Genetics Breeding, and Genetic Resources. Sinauer: Sunderland, MA, pp 254-277.

Braverman JM, Hudson RR, Kaplan NL, Langley CH, Stephan W (1995). The hitchhiking effect on the site frequency spectrum of DNA polymorphism. Genetics 140: 783-796.

Carson HL (1968). The population flush and its genetic consequences. In: Lewontin RC (ed) Population Biology and Evolution. Syracuse University Press: New York, pp 123-137.

Carson HL (1997). Sexual selection: a driver of genetic change in Hawaiian Drosophila. J Heredity 88: 343-352.

Carson HL, Clague DA (1995). Geology and biogeography of the Hawaiian islands. In: Wagner WL, Funk VA (eds) Hawaiian Biogeography: Evolution on a Hot Spot Archipelago. Smithsonian Institute Press:Washington, DC, pp 14-29.

Cross HB, Motley TJ (2000). Molecular systematics of Hawaiian Peperomia. Am J Bot 87: 173.

Cummings MP, Clegg MT (1998). Nucleotide sequence diversity at the alcohol dehydrogenase 1 locus in wild barley (Hordeum vulgare ssp spontaneum): an evaluation of the background selection hypothesis. Proc Natl Acad Sci USA 95: 5637-5642.

Delichère $C$, Veuskens J, Hernould $M$, Baarbacar N, Mouras A, Negrutiu I, Moneger F (1999). SlY1, the first active gene cloned from a plant $\mathrm{Y}$ chromosome encodes a WD-repeat protein. EMBO J 18: 4169-4179.

Eanes WF, Kirchner M, Taub DR, Yoon J, Chen J (1996). Amino acid polymorphism and rare electrophoretic variants of G6PD from natural populations of Drosophila melanogaster. Genetics 143: 401-406.

Excoffier L (2000). Arlequin: A Software for Population Genetics Data Analysis. Program manual, University of Geneva: Switzerland. http://anthro.unige.ch/arlequin.

Fay JC, Wu C-I (2000). Hitchhiking under positive Darwinian selection. Genetics 155: 1405-1413.

Fernandez A, Toro MA, Lopez-Fanjul C (1995). The effect of inbreeding on the redistribution of genetic variance of fecundity and viability in Tribolium castaneum. Heredity 75 : 376-381.

Filatov DA (2002). ProSeq: a software for preparation and evolutionary analysis of DNA sequence datasets. Mol Ecol Notes 2: 621-624.

Filatov DA, Charlesworth D (1999). DNA polymorphism, haplotype structure and balancing selection in the Leavenworthia PgiC locus. Genetics 153: 1423-1434.

Filatov DA, Laporte V, Vitte C, Charlesworth D (2001). DNA diversity in sex linked and autosomal genes of the plant species Silene latifolia and S. dioica. Mol Biol Evol 18: 1442-1454.

Filatov DA, Moneger F, Negrutiu I, Charlesworth D (2000). Low variability in a Y-linked plant gene and its implications for Y-chromosome evolution. Nature 404: 388-390.

Fu Y-X (1997). Statistical tests of neutrality of mutations against population growth, hitchhiking and background selection. Genetics 147: 915-925.

Funk VA, Wagner WL (1995). Biogeographic patterns in the Hawaiian islands. In: Wagner WL, Funk VA (eds) Hawaiian Biogeography. Evolution on a Hot Spot Archipelago. Smithsonian Institute Press: Washington, DC, pp 379-419.

Gaut BS, Clegg MT (1993). Nucleotide polymorphism in the Adh1 locus of pearl millet (Pennisetum glaucum) (Poaceae). Genetics 135: 1091-1097.

Helenurm K, Ganders FR (1985). Adaptive radiation and genetic differentiation in Hawaiian Bidens. Evolution 39: 753-765.
Hollocher H (1996). Islands hopping in Drosophila: patterns and processes. Philos Trans R Soc Lond Ser B 351: 735-743.

Hudson RR (1990). Gene genealogies and the coalescent process. Oxf Surv Evol Biol 7: 1-45.

Hudson RR, Bailey K, Skarecky D, Kwiatowski J, Ayala FJ (1994). Evidence for positive selection in the superoxide dismutase region of Drosophila melanogaster. Genetics 136: 1329-1340.

Hudson RR, Boos DD, Kaplan NL (1992). A statistical test for detecting geographic subdivision. Mol Biol Evol 9: 138-151.

Kuittinen H, Aguade M (2000). Nucleotide variation at the CHALCONE ISOMERASE locus in Arabidopsis thaliana. Genetics 155: 863-872.

Kumar S, Tamura K, Nei M (1993). MEGA: Molecular Evolutionary Genetics Analysis, Version 1.0. The Pennsylvania State University: University Park, PA.

Lawton-Rauh A, Robichaux RH, Purugganan MD (2003). Patterns of nucleotide variation in homoeologous regulatory genes in the allotetraploid Hawaiian silversword alliance (Asteraceae). Mol Ecol 12: 1301-1313.

Lindqvist C, Albert VA (2002). Origin of the Hawaiian endemic mints within North American Stachys (Lamiaceae). Am J Bot 89: 1709-1724.

Liu F, Charlesworth D, Kreitman M (1999). The effect of mating system differences on nucleotide diversity at the phosphoglucose isomerase locus in the plant genus Leavenworthia. Genetics 151: 343-357.

Marr KL, Bohm BA (1999). Allozyme variation in endemic Hawaiian Lysimachia (Primulaceae). Syst Bot 24: 545-557.

Mayr E (1963). Animal Species and Evolution. Harvard University Press: Cambridge, MA.

Meffert L (2000). The evolutionary potential of morphology and mating behaviour: the role of epistasis in bottlenecked populations. In Wolf JB, Broodie ED, Wade MJ (eds) Epistasis and the Evolutionary Process. Oxford University Press: New York, pp 177-193.

Moriyama EN, Powell JR (1995). Intraspecific nuclear DNA variation in Drosophila. Mol Biol Evol 13: 261-277.

Pax DL, Price RA, Michaels HJ (1997). Phylogenetic position of the Hawaiian geraniums based on $r b c L$ sequences. Am J Bot 84: $72-78$

Rogers AR, Harpending H (1992). Population growth makes waves in the distribution of pairwise genetic differences. Mol Biol Evol 9: 552-569.

Sakai AK, Weller SG, Wagner WL, Soltis PS, Soltis DE (1997). Phylogenetic perspective on the evolution of dioecy: adaptive radiation in the endemic Hawaiian genera Schiedea and Alsinidendron (Caryophyllaceae: Alsinoideae). In: Givnish TJ, Sytsma KJ (eds) Molecular Evolution and Adaptive Radiation. Cambridge University Press: New York, pp 445-473.

Savolainen O, Langley CH, Lazzaro BP, Freville H (2000). Contrasting patterns of nucleotide polymorphism at the alcohol dehydrogenase locus in the outcrossing Arabidopsis lyrata and in the selfing Arabidopsis thaliana. Mol Biol Evol 17: 645-655.

Schneider S, Excoffier L (1999). Estimation of past demographic parameters from the distribution of pairwise differences when the mutation rates vary among sites: application to human mitochondrial DNA. Genetics 152: 1079-1089.

Soltis PS, Soltis DE, Weller SG, Sakai AK, Wagner WL (1996). Molecular phylogenetic analysis of the Hawaiian endemics Schiedea and Alsinidendron (Caryophyllaceae). Syst Bot 21: 365-379.

Tajima F (1989). Statistical method for testing the neutral mutation hypothesis by DNA polymorphism. Genetics 123 585-595.

Templeton AR (1980). The theory of speciation via the founder principle. Genetics 94: 1011-1038.

Terauchi R, Terachi T, Miyashita NT (1997). DNA polymorphism at the Pgi locus of a wild yam, Dioscorea tokoro. Genetics 147: 1899-1914. 
Thomson JD, Gibson TJ, Plewniak F, Jeanmougin F, Higgins DG (1997). The CLUSTAL_X windows interface: flexible strategies for multiple sequences alignment aided by quality analysis tools. Nucl Acids Res 25: 4876-4882.

Veuille M, King LM (1995). Molecular basis of polymorphism at the Esterase-5B locus in Drosophila pseudoobscura. Genetics 141: 255-262.

Wagner WL, Funk VA (eds) (1995). Hawaiian Biogeography: Evolution on a Hot Spot Archipelago. Smithsonian Institute Press: Washington, DC.

Wagner WL, Weller SG, Sakai AK (1995). Phylogeny and biogeography in Schiedea and Alsinidendron (Caryophyllaceae). In: Wagner WL, Funk VA (eds) Hawaiian Biogeography:
Evolution on a Hot Spot Archipelago. Smithsonian Institute Press: Washington, DC, pp 221-258.

Weller SG, Sakai AK, Straub C (1996). Allozyme diversity and genetic identity in Schiedea and Alsinidendron (Caryophyllaceae: Alsinoideae) in the Hawaiian islands. Evolution 50: 23-34.

Weller SG, Sakai AK, Wagner WL (2001). Artificial and natural hybridization in Schiedea and Alsinidendron (Caryophyllaceae: Alsinoideae): the importance of phylogeny, genetic divergence, breeding system, and population size. Syst Bot 26: 571-584.

Weller SG, Wagner WL, Sakai AK (1995). A phylogenetic analysis of Schiedea and Alsinidendron (Caryophyllaceae: Alsinoideae): implications for the evolution of breeding systems. Syst Bot 20: 315-337. 